\title{
Supply Chain Management in Higher Education: A Conceptual Model Within COVID-19 Outbreak, Building a Proposed Conceptual Model
}

\author{
https://doi.org/10.3991/ijet.v16i13.21845 \\ Ashraf Badawood \\ University of Jeddah, Jeddah, Kingdom of Saudi Arabia \\ ambadawood@uj.edu.sa
}

\begin{abstract}
This research examines the application of supply chain management concepts in the higher education institutions in the Gulf region. It presents the value chain in institutions of higher education. The value chain consists of inputs, procedure and outputs. The common variables in the academic supply chain are information and shared value across the chain that can translate into strategic and functional objectives of the learning institution. The success of the supply chain management model depends on the level of integration and collaboration among the stakeholders starting from high schools as inputs of higher education. The main objective of the supply chain management model is to create better output. The output is from the practicality of research explored to the various industries and the level of skills of qualified graduates.
\end{abstract}

Keywords - COVID-19, supply chain management, higher education, value chain, conceptual model

\section{Introduction}

The Gulf region is highly developed and is characterized by dynamic and diverse opportunities created by the increase in large projects that have improved the quality of life of citizens. This creates pressure for the government to avail the needed competence, education and skills to better utilize these developments [1]. Within the gulf region, there are many local higher education institutions while others are established in collaboration with international universities [2]. Within this region, Institutions of higher education are increasingly required to improve the quality of outcomes, tackle competition from international universities, adapt to the rise in globalization as well as address the intricacies of their operations [3]. The other key pressure faced by higher education (thereafter referred to as HE) institutions is the current COVID-19 crisis which limits the level of face-to-face interaction allowed between learners and the faculty staff in order to contain the epidemic [4].

Supply chain management (SCM) is a concept that is prevalent in the manufacturing industry but less so in the service industry [5]. However, it is an important area of management since it deals with the flow of services and includes all processes re- 
quired to transform inputs into the final product. A simple view of SCM in the HE institutions is that inputs are learners while the process is the programs offered and the output is the graduating students who are competent to work in the job market. The conceptual model adopted for supply chain management becomes increasingly important in HE in order to explore competitive advantages that can be realized through knowledge sharing platforms, better outsourcing of inputs, increased customer satisfaction, improved operations and increasing revenue. An optimal SCM in higher education institutions can improve the quality of education in the current environment within the Gulf region [6].

According to Gravili et al. [7], the supply chain management model applied by higher education institutions assists in integrating and optimizing activities within the institution as well as across it to ensure that all stakeholders realize expected value and satisfaction. In the normal context, supply chain is mostly used to define the value chain applicable in production of goods: input is received from suppliers, value is added to the inputs and the final output is made available to the customers [8]. However, supply chain management is applicable in the service industry. According to Khan and $\mathrm{Yu}$ [9], the supply chain management in $\mathrm{HE}$ is unique because the output is usually the quality of education and research with an aim of enhancing the value experienced by society. In HE, the main supplier of inputs is usually the customer themselves. They avail themselves physically, mentally and through the information they provide. This becomes the input to the service process in the supply chain of learning institutions [10].

This current study looks at the various variables in the supply chain model in the higher education institutions. The aim of this research is to build a conceptual model that would be appropriate in the Gulf region amidst COVID-19 and other environmental pressures.

\section{$2 \quad$ Research Problem}

Ebrahim et al. [11] state that with the evolving environment that HE institutions operate in and with the current crisis caused by COVID-19, HE institutions are advancing their supply chain management models to ensure closer collaboration with all the variables in the model such as secondary schools that provide students, its current students, university staff and the future employers of the graduates. The aim of this study is the build a SCM model that can be used by the HE institutions to enhance collaboration in the value chain in order to realize integration within the supply chain. The gap that has been identified is the lack of information on the stakeholders that are in the supply chain of the HE institutions [12]. To realize this aim, two major questions would be explored in this study:

- What are the previous studies' conclusions on role of supply chain management in higher education institutions, mainly in the Gulf region?

- Which conceptual models, based on supply chain management concepts, can be used to enhance higher education outcomes mainly in the Gulf region? 


\section{Significance of the Study}

This study is on the conceptual models that can be applied in supply chain management to improve higher education within the Gulf region. Previous studies have explored areas such as curriculum development and the use of technology to enhance learning. The current research is significant since it will reduce the current gaps that exist on the various implementation models that exist to reduce the inefficiencies and ineffective in supply chain system for HE institutions [10]. The significance of this research arises from looking at best practice in supply chain management in the developed countries and applying this in coming up with the concepts that would be applicable in the Gulf region. This research will also factor in the global crisis that has been brought about by COVID-19 [11]. It will explore ways in which SCM can mitigate against this crisis as it addresses other gaps. This research is also insightful, as it will reduce the gap that is prevalent due to lack of comparable studies on the research area.

\section{$4 \quad$ Limitations of the Study}

The main limitation of this research has been the use of systematic literature review (SLR) as the methodology. The SLR is a rigorous, comprehensive and convenient way of outlining previous research, which is relevant to the current study. Carrying out a SLR is more applicable than gathering primary data due to the prevailing COVID-19 epidemic being experienced in the gulf region. However, there are some key limitations to using SLR such as lack of ownership over the primary data collection process. Additionally, the data collected under SLR is not the most recent, accurate and relevant in the prevailing COVID-19 epidemic as compared to what would have been collected by primary research.

\section{Operational Definition}

This research used concise, relevant and a broad operational definition to outline the method used in the study. In order for the study to be strong and impactful, it is important that the data collected is appropriate and applicable [13]. In research, the operational definition is essential to guide the investigator in making decisions on the usefulness and relevance of data to minimize uncertainty of findings and bias. In most instances, the data collection process would be ineffective if operational definition on the suitability and timeliness of data was not provided in the research.

The researcher was keen on ensuring data collection was effective. Consequently, a stable approach was applied in data collection. To achieve this, the investigator defined the data collection approach to minimize the chance of collecting biased and unreliable data. The operational definition applied was broad to ensure that the investigator minimized any discrepancy in data collection for this research. A list is provided below on the operational definitions applied in this research. 
Characteristic of interest: A conceptual model of supply chain management in higher education within COVID-19 outbreak

Measuring instrument: Data gathered by the investigator was from online technical sources and from the physical library.

Test method: The researcher collected and analyzed data from more than 25 scientific sources. Data published in 2017 onwards was what the researcher relied on in this study.

Decision criteria: Systematic analysis of data that was collected from diverse sources. Data analyzed for this study was printed in year 2017 or in proceeding years. Data that was not from authoritative sources for instance manuscripts was not used in this research.

\section{Previous Studies}

According to Hugos [14], Supply chain refers to a system of facilities coupled with delivery options that carry out a series of function: procurement of the input, processing the input and delivery of the output to customers. Supply chain management model is a strategy in which these diverse functions can be realized. Most literature on supply chain management in the Gulf region relates to goods, which are physically produced in the manufacturing sector [15]. There has been less literature published on supply chain in the service industry. However, there has been growth in academic interest in promoting services in higher learning institutions [16]. In service establishments, the major input is usually customers themselves who avail themselves, their mental faculties and information as the main inputs to the value chain [9]. The conceptual models used in service industries to operate SCM are similar to those in use in the manufacturing industry. There exist three commercial forces that support decision making in SCM: technology, globalization and expectations from customers [17].

Supply chain management concept in higher learning institutions is characterized by the educational value chain. Ahmed [10] proposed that the educational value chain could be used as a tool to prepare strategically plans in the tertiary education sector. Walden [18] also investigated the educational value chain taking into account diverse aspects. According to Walden (2020), the educational value chain comprise of two distinct supply chains: student value chain and the research value chain. Bugawa et al. [19] presents that one of the main objectives of educational value chain is to improve the proficiency of the customer who is an integral component of society. To realize this objective, the HE institutions should have knowledge of the stakeholders in the value chain including suppliers (secondary schools), customers (graduates and future employers) and consumers (society) [20]. The success of the education value chain is in the continuous coordination of the stakeholders in the value chain for desired output. This is represented in a simple supply chain model below (figure 1) [21]. 


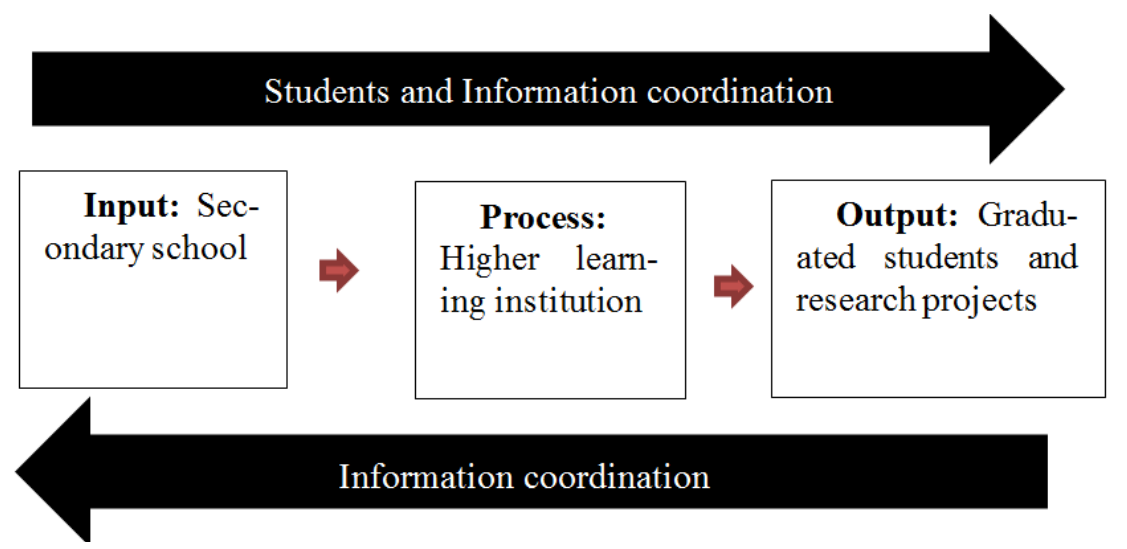

Fig. 1. Simple supply chain model

For HE institutions, the value chain has simple and identifiable inputs. Some of these inputs are linked to a service while others relate to other overheads [2]. An upstream chain exists within this value chain and this moves the supplies to the service providers [22]. The SCM aims at transforming as well as moving the input along in the value chain so that the institution can satisfy the customers [23]. The chain can be illustrated as a system where information and students are moving downstream to create the desired output. Different concepts about the high education value chain have been derived from combining the inputs differently in the system say by the application of technology through eLearning and other programs to ensure the output is of the desired quality [24].

\section{$7 \quad$ Research Method and Procedures}

\subsection{Methodology}

This study applied deep systematic literature review (DSLR), which is a secondary research methodology. By employing the DSLR method, the investigator identified and collected scientific data from high ranked journal articles specializing in the topic. These top ranked journal articles from databases like ProQuest was reviewed so as to contribute to the research area on the conceptual model of supply chain management in higher education while being cognizant of the current crisis occasioned by COVID19 in the gulf region [25]. To find the rankings for the journal, individual journals were searched for and selected. By scrolling down, the rankings on the journal impact factor could be observed, according to the Journal Citation Report (JCR). Apart from that, the Google Scholar rankings were also used, which could be found via the Google Scholar Metrics. Data collected related to conceptual models, on higher education supply chain management and was relevant to the gulf region. This criteria was useful as it helped maintain focus on relevant sources. For instances, supply chain management conceptual models that were not applicable to the gulf countries were 
not considered. For database search, the investigator used the following keywords: SupplyChainManagement+HigherEducation+COVID-19+Gulf as well as synonyms. For example, a synonym used for Covid-19 was 'corona virus', whereas a synonym used for higher education was tertiary education. This methodology applied this inclusion criterion. Additionally, the investigator limited review to studies printed post 2017. The investigator considered abstracts of sixty journal articles. On evaluating the abstracts, the investigator eliminated the sources that did not meet inclusion requirements, such as not highlighting methodology used. Thirty sources were retained for present study.

The researcher carried out further screening of the thirty sources. This in-depth screening of studies contained in those journal articles was necessary to develop findings of the studies in order to respond adequately to research questions identified earlier in present research project. The researcher evaluated the full texts of studies that met the inclusion criteria as to collect data that had depth, relevance and reliability [21].

One database was the university library was the source of the most online studies used in the DSLR. This was complemented by using the ProQuest database, and the Google Scholar search engine, all which were online. Using online databases to carry out research was suitable and expeditious especially due to the current COVID-19 crisis in the gulf region. During this crisis, the researcher would not have been in a position to visit physical libraries and peruse journals. Online sources also increased the breadth of materials accessible to the researcher, making the DSLR highly convenient for present project [26].

\subsection{Procedure followed to draw conclusion}

In order to reach conclusions for the study, the investigator selected studies according to the inclusion criteria and thoroughly read the full content of the studies so as to understand the different viewpoints of authors. The viewpoints of diverse authors were compared to identify divergences and convergences in ideas. Careful analysis of the authors' observations was carried out to identify and subsequently minimize bias that is normally prevalent in secondary research. The researcher relied on a spreadsheet in the extraction of data from studies. Entries in the worksheet were around thirty corresponding to the number of studies reviewed. Once data was extracted, the content analysis was carried out by investigator through reading the content several times. Thereafter, codes were allocated to recurring patterns identified in the studies. Those codes were later grouped into broader categories called findings. These are the findings that are in this study. A critical analysis of the findings was carried out in order to arrive at conclusions. To enhance the objectivity of the research process, the investigator followed research ethics that required that participants who had been used in the original research remained anonymous and not become de-identified in secondary research. The investigator applied a broad methodology that showed the steps used to get to the conclusions [27]. 


\section{$8 \quad$ Results of the Study}

The findings from the systematic literature review could be described under two categories:

\subsection{Finding 1: Conceptual models in HE supply chain management are evolving but are facing some challenges in the Gulf region}

Abdel-Baset et al. [28] state that the supply chain management model is an integrated system that involved collaboration and information sharing for the entire value chain in the HE institutions. Further research conducted by Hong, Zhang and Ding [17] observed that information about customer preference is one of the most important factors in generating value in SCM. Higher learning institutions have multiple upstream and downstream providers who are interlinked into a large system. It has been found that this creates a large network of interdependency say between the government and the institution in provision of sponsorship to the students [29]. It has been found that information sharing between the different stakeholders in the higher education value chain has been lacking to facilitate planning for SCM. Information has been found to be an integral component of SCM since the HE institutions need to focus on the value chain holistically in order to deliver quality product and services suitable for the job market and society. This information is important since it assists in coming up with the best practice metrics to develop efficient as well as effective processes in the value chain [6].

Studies found that technology has been critical in bridging the information gap that exists in the HE institutions' value chain especially in the Gulf region. These institutions are developing online tools such as information sharing platforms to ensure visibility of the upstream and downstream activities. Some of these tools used include social media and eLearning programs. Abdulwahed [30] stresses the importance of adopting technology to improve the value chain for these institutions. As a result of technology, it has been found that information is becoming more accessible and being used to facilitate SCM [31]. This has been found to be particularly useful during COVID-19 crisis in order to plan for the continuation of service provision to stakeholders [12].

\subsection{Finding 2: Supply chain management models strengthen the quality of higher learning offered by institutions}

Studies by Habes et al. [32] observed that developing the human resource of a country by equipping them with knowledge and skills offered in HE institutions results in further development of the country. One of the strategies applied has been the application of an integrated model of SCM in higher education in order to increase the competitive ability of the Gulf region [29]. As a result, HE institutions are required to improve every aspect of their value chain. Attia and Eldin [23] state that optimal value chain activities are achieved through developing a SCM model that has dynamic 
capabilities which allow for information to flow to all stakeholders so as to support expeditious and relevant decision-making process. Studies done by Arbaugh et al. [22] show that an ideal SCM model allows for knowledge management process, which involves the creation, storing and distribution of information. Higher learning institutions are focusing on optimizing the efficiency and effectiveness of every activity in the value chain from upstream to downstream in order to respond to the demand of their customers [33].

Studies by Walden [18] have found that employers have undergone various changes in recent times including the use of innovative ways of doing business. This has been brought about by the requirement of organizations (employers) to be highly competitive due to internal and external pressures brought about by globalization and other factors such as the COVID-19 crisis [3]. As a result, the output (graduated students) needs to have competences and knowledge that can enable them to work more efficiently to maximize output and production [20]. Khan and $\mathrm{Yu}$ [9] observed that this is addressed by the process improvements that are being undertaken by higher learning institutions through provisions of innovative programs and use of technology in their value chain. Additionally, higher learning institutions have been found to adopt innovations in SCM for both the student value chain as well as the research value chain [21].

\section{Conclusions and Recommendations}

Higher education institutions should ensure that the supply chain management model is sufficiently robust and proactive in the Gulf region in order to cope with internal pressures such as COVID-19 crisis and external pressures such as globalization and technological innovations. To accomplish this, it is important that the SCM undergoes continuous changes, carries out process integration and ensures the flow of dynamic as well as collaborative information upstream and downstream. The various components in the value chain are interrelated and therefore should be integrated to cater for the various stakeholder needs. To facilitate this integration, interaction should be continuous between the stakeholders; with the higher education institutions taking a central role in this interaction. The model should be able to facilitate the identification of all the stakeholders and their subsequent needs. This is a prerequisite to developing an impactful model. For instance, the output of this model should be based on what the business world needs while the process in the value chain should be innovative to take care of diverse learners' needs.

The model shows in figure 2 depicts a supply chain management system with the various inputs, processes and outputs. It shows that best practice has been considered in integrating the whole value chain. This was done through identification of all stakeholders and their needs as facilitated by collection of information. A model that can assist the students and their families at any one point to make decision through provision of timely information can affect the future of the students and eventually the society positively. It is recommended that the information provided should be of good quality and predictive in nature, that is to mean that it should offer insights and statics 
of the various options available to the stakeholders in the value chain. The stakeholders in

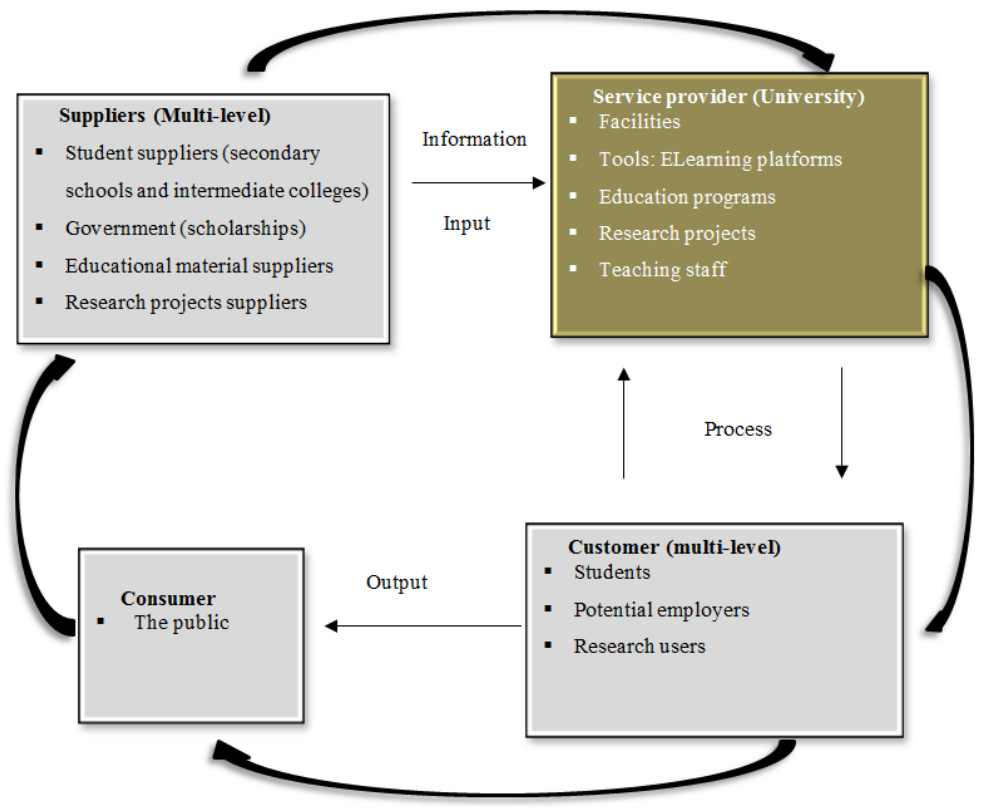

Fig. 2. Integrated conceptual model for higher education institutions

The value chain should be in a position to interact through the dynamic dimensions presented by the institution in order to cope with the changes that may occur due to innovations, changes in employer requirements and the changes occasioned by the diversity of the learners in today's higher education market.

\section{References}

[1] David, S. A., Taleb, H., Scatolini, S. S., Al-Qallaf, A., Al-Shammari, H. S., \& George, M. A. (2017). An exploration into student learning mobility in higher education among the Arabian Gulf Cooperation Council countries. International Journal of Educational Development, 5(5), 41-48. https://doi.org/10.1016/j.ijedudev.2017.05.001

[2] Yan, Y., Zheng, X., Wang, S., Yang, G., \& Zhang, J. (2019). A Collaborative Environmental Education Pattern of Deepening the Integration of Production and Education based on Application-Oriented Undergraduate Teaching: A Case Study in Civil Engineering (Major of Beibu Gulf University).Ekoloji Dergisi, (107).

[3] Al Shboul, M. D. A., Garza-Reyes, J. A., \& Kumar, V. (2018). Best supply chain management practices and high-performance firms: The case of Gulf manufacturing firms. International Journal of Productivity and Performance Management,67(9), 77. https://doi. org/10.1108/ijppm-11-2016-0257

[4] Ebrahim, S. H., \& Memish, Z. A. (2020). Saudi Arabia's drastic measures to curb the COVID-19 outbreak: temporary suspension of the Umrah pilgrimage. Journal of Travel Medicine, 27(3), 29. https://doi.org/10.1093/jtm/taaa029 
[5] Mangla, S. K., Luthra, S., Mishra, N., Singh, A., Rana, N. P., Dora, M., \& Dwivedi, Y. (2018). Barriers to effective circular supply chain management in a developing country context. Production Planning \& Control, 29(6), 551-569. https://doi.org/10.1080/0953728 7.2018 .1449265

[6] Agi, M. A., \& Nishant, R. (2017). Understanding influential factors on implementing green supply chain management practices: An interpretive structural modelling analysis. Journal of environmental management,18(8), 351-363. https://doi.org/10.1016/j.jenvman .2016.11.081

[7] Gravili, G., Benvenuto, M., Avram, A., \& Viola, C. (2018). The influence of the Digital Divide on Big Data generation within supply chain management. The International Journal of Logistics Management 5(3), 4-10. https://doi.org/10.1108/ijlm-06-2017-0175

[8] Al-Esmael, B., Talib, F., Faisal, M. N., \& Jabeen, F. (2019). Socially responsible supply chain management in small and medium enterprises in the GCC. Social Responsibility Journal 3(1), 5-10. https://doi.org/10.1108/srj-09-2017-0174

[9] Khan, S. A. R., \& Yu, Z. (2019).Strategic supply chain management (pp. 1-290). New York: Springer.

[10] Ahmed, A. I. (2018). Understanding the factors affecting the adoption of green computing in the Gulf Universities. International Journal of Advanced Computer Science and Applications, 9(3), 304-3011.

[11] Ebrahim, S. H., Ahmed, Q. A., Gozzer, E., Schlagenhauf, P., \& Memish, Z. A. (2020). Covid-19 and community mitigation strategies in a pandemic Journal of Travel Medicine, 29(4), 40. https://doi.org/10.1136/bmj.m1066

[12] Hamilton, L. S., Kaufman, J. H., \& Diliberti, M. (2020). Teaching and Leading Through a Pandemic: Key Findings from the American Educator Panels Spring 2020 COVID-19 Surveys. https://doi.org/10.7249/rra168-2

[13] Azeroual, O., Saake, G., \& Schallehn, E. (2018). Analyzing data quality issues in research information systems via data profiling. International Journal of Information Management, 4(1), 50-56. https://doi.org/10.1016/j.ijinfomgt.2018.02.007

[14] Hugos, M. H. (2018). Essentials of supply chain management. New Jersey: John Wiley \& Sons.

[15] Koberg, E., \& Longoni, A. (2019). A systematic review of sustainable supply chain management in global supply chains.Journal of cleaner production,20(7), 1084-1098. https:// doi.org/10.1016/i.jclepro.2018.10.033

[16] Tseng, M. L., Islam, M. S., Karia, N., Fauzi, F. A., \& Afrin, S. (2019). A literature review on green supply chain management: Trends and future challenges. Resources, Conservation and Recycling, 14(1), 145-162. https://doi.org/10.1016/j.resconrec.2018.10.009

[17] Hong, J., Zhang, Y., \& Ding, M. (2018). Sustainable supply chain management practices, supply chain dynamic capabilities, and enterprise performance. Journal of Cleaner Production, 17(2), 3508-3519. https://doi.org/10.1016/j.jclepro.2017.06.093

[18] Walden, J. (2020). Supply Chain Management Systems and Curriculum Reviews: What Are We Teaching About Supply Chain Management Systems? Do We Need to Modify Our Curriculums? International Journal of Contemporary Education, 3(2), 1-10. https://doi.org/10.11114/ijce.v3i2.4861

[19] Bugawa, A., Al-Jayyousi, O., Alsultanny, Y., Bhandari, M., \& Mirzal, A. (2018). An overview on professional education development in technology management: The experience of Arabian Gulf University. Asia-Pacific Journal of Educational Management Research, $3(1), 39-48$.

[20] Younis, H., \& Sundarakani, B. (2019). The impact of firm size, firm age and environmental management certification on the relationship between green supply chain practices and corporate performance. Benchmarking: An International Journal 2(1), 3-9. https://doi.org/ $\underline{10.1108 / \mathrm{bij}-11-2018-0363}$ 
[21] Manatos, M. J., Sarrico, C. S., \& Rosa, M. J. (2017). The integration of quality management in higher education institutions: A systematic literature review. Total Quality Management \& Business Excellence,28(1-2), 159-175. https://doi.org/10.1080/14783363.2015. 1050180

[22] Arbaugh, J. B., Asarta, C. J., Hwang, A., Fornaciari, C. J., Bento, R. F., \& Dean, K. L. (2017). Key authors in business and management education research: Productivity, topics, and future directions. Decision Sciences Journal of Innovative Education, 15(3), 268-302. https://doi.org/10.1111/dsji.12131

[23] Attia, A., \& Eldin, I. E. (2018). Organizational learning, knowledge management capability and supply chain management practices in the Saudi food industry. Journal of Knowledge Management 3(2), 115-120. https://doi.org/10.1108/jkm-09-2017-0409

[24] Visvizi, A., Lytras, M. D., \& Sarirete, A. (Eds.). (2019). Management and Administration of Higher Education Institutions at Times of Change. Bingley: Emerald Publishing Limited. https://doi.org/10.1108/9781789736274

[25] Xiao, Y., \& Watson, M. (2019). Guidance on conducting a systematic literature review. Journal of Planning Education and Research, 39(1), 93-112.

[26] Al-Kurdi, O., El-Haddadeh, R., \& Eldabi, T. (2018). Knowledge sharing in higher education institutions: a systematic review. Journal of Enterprise Information Management 6(4), 45-100. https://doi.org/10.1108/jeim-09-2017-0129

[27] Boelens, R., De Wever, B., \& Voet, M. (2017). Four key challenges to the design of blended learning: A systematic literature review. Educational Research Review, 2(2), 1-18. https://doi.org/10.1016/j.edurev.2017.06.001

[28] Abdel-Baset, M., Chang, V., \& Gamal, A. (2019). Evaluation of the green supply chain management practices: A novel neutrosophic approach. Computers in Industry, 10(8), 210220. https://doi.org/10.1016/i.compind.2019.02.013

[29] Luthra, S., \& Mangla, S. K. (2018). When strategies matter: adoption of sustainable supply chain management practices in an emerging economy's context. Resources, Conservation and Recycling, 13(8), 194-206. https://doi.org/10.1016/j.resconrec.2018.07.005

[30] Abdulwahed, M. (2017). Technology Innovation and Engineering' Education and Entrepreneurship (TIEE) in engineering schools: Novel model for elevating national knowledge based economy and socio-economic sustainable development. Sustainability, 9(2), 171. https://doi.org/10.3390/su9020171

[31] Daniela, L., Strods, R., \& Kalniņa, D. (2019). Technology-Enhanced Learning (TEL) in Higher Education: Where Are We Now? In Knowledge-intensive economies and opportunities for social, organizational, and technological growth (pp. 12-24). London: IGI Global. https://doi.org/10.4018/978-1-5225-7347-0.ch002

[32] Habes, M., Salloum, S. A., Alghizzawi, M., \& Alshibly, M. S. (2018). The role of modern media technology in improving collaborative learning of students in Jordanian universities. International Journal of Information Technology and Language Studies, 2(3), 71-82.

[33] Moh'd Anwer, A. S., Garza-Reyes, J. A., \& Kumar, V. (2018). Best supply chain management practices and high-performance firms. International Journal of Productivity and Performance Management 9(6), 31-38.

\section{Author}

Ashraf Badawood works in the College of Business, MIS, University of Jeddah, Jeddah, Kingdom of Saudi Arabia

Article submitted 2021-02-07. Resubmitted 2021-02-28. Final acceptance 2021-02-28. Final version published as submitted by the authors. 